\title{
MARGIN AND TRANSCENDENCE
}

In memory of Siddalingaiah, poetic voice of the Dalit movement

\section{EDITORIAL AND INTRODUCTION}

Laurence Simon and Sukhadeo Thorat

\section{ARTICLES}

A Commentary on Ambedkar's Posthumously Published "Philosophy of Hinduism" - Part III Rajesh Sampath

Norm Entrepreneurship at the UN - Dalits and Communities Discriminated on Work and Descent Paul Divakar Namala

Ambedkar and the Buddha's Sangha: A Ground for Buddhist Ethics Timothy Loftus

Reading Dalit Autobiographies in English: A Top Ten List Christopher Queen

Ethnic Identity, Discrimination and the Shaping of Remittance Culture in Ghana Joseph Kweku Assan

A Critique of Sanskritization from Dalit/Caste-Subaltern Perspective Ishita Roy

Exclusion of Tribal Women from Property Inheritance Rights: A Study of Tripuri Women of India Ashim Shil and Hemraj $P$ Jangir

On the Margins of Healthcare: Role of Social Capital in Health of Migrants in India Shriyuta Abhishek and Nanda Kishore Kannuri

Tending Immanence, Transcending Sectarianism: Plane of Mixed Castes and Religions Roshni Babu

\section{FORUM}

Ari Varutada A Poem by Chandni Girija

Reflection A Poem by Gaurav J. Pathania

CASTE: A Global Journal on Social Exclusion is collaborating with JSTOR to digitize,

JSTOR preserve, and extend access to our journal
BOOK, ESSAY, FILM REVIEW

Spotted Goddesses: Dalit Women's Agency-narratives on Caste and Gender Violence Balmurli Natrajan

Dalit-Bahujan Feminism:

A Newly Emerging Discourse Kancha Ilaiah Shepherd

Retro-Modern India

Zeeshan Husain

Caste, Gender and Fire in Maadathy: an Unconventional Fairy Tale Roja Suganthy-Singh

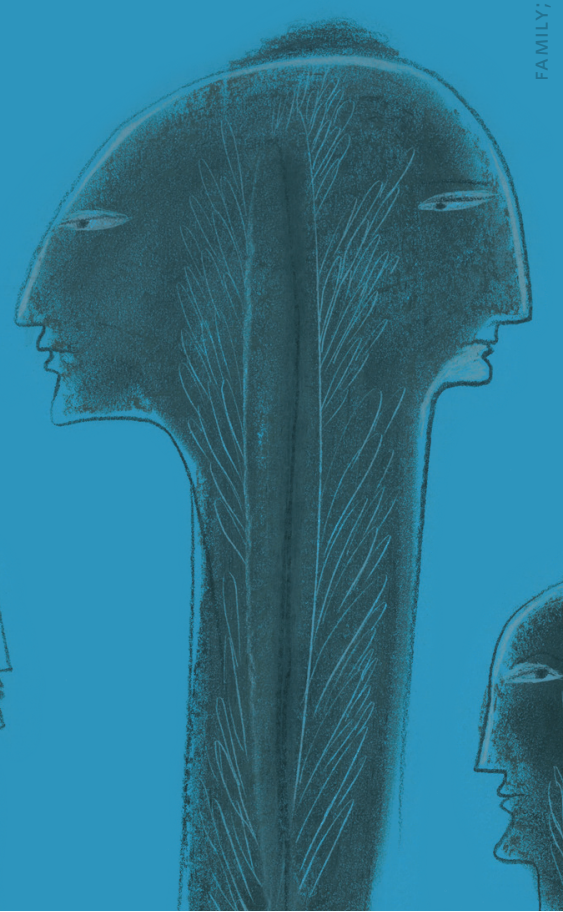




\section{CASTE \\ A GLOBAL JOURNAL ON SOCIAL EXCLUSION}

MARGIN AND TRANSCENDENCE

VOLUME 2, NUMBER 2

$\infty<\infty<\infty<\infty<\infty<\infty$

JOINT EDITORS-IN-CHIEF

Laurence R. Simon

Brandeis University, USA

Sukhadeo Thorat

(Emeritus) Jawaharlal Nehru University, India

EDITOR

Joseph K. Assan

Brandeis University, USA

REVIEWS EDITOR

Jebaroja Singh

St. John Fisher College, USA

SENIOR EDITORIAL ASSISTANT

Afia A. Adaboh

Brandeis University, USA

EDITORIAL ASSISTANT FOR PUBLIC

OUTREACH \& COMMUNICATIONS

Jaspreet Mahal

Brandeis University, USA

PRODUCTION EDITOR

Vinod Kumar Mishra

Indian Institute of Dalit Studies, India

UNIVERSITY LIBRARIAN

Matthew Sheehy

Brandeis University, USA

OJS TECHNICAL MANAGER

Brian Meuse

Brandeis University Library, USA 
Kaushik Basu, C. Marks Professor of International Studies and Professor of Economics, Cornell University, USA; former Chief Economist of the World Bank; President, International Economics Association; former Chief Economic Adviser to the Government of India

Krishna Bhattachan, Professor Emeritus of Sociology, Tribhuvan University, Nepal

Kevin D. Brown, Professor of Law, Maurer School of Law, Indiana University, USA

Ipsita Chatterjee, Associate Professor, Department of Geography and the Environment, University of North Texas, USA

Ashwini Deshpande, Professor of Economics, Ashoka University, India

Meena Dhanda, Professor in Philosophy and Cultural Politics, University of Wolverhampton, United Kingdom

Jean Drèze, Honorary Professor, Delhi School of Economics, University of Delhi, India

Ashok Gurung, Associate Professor, Julien J. Studley Graduate Program in International Affairs, The New School, New York, USA

John Harriss, Professorial Research Associate, Department of Development Studies, SOAS University of London, United Kingdom

Eva-Maria Hardtmann, Associate Professor and Director of Studies, Department of Social Anthropology, Stockholm University, Sweden

Susan Holcombe, Professor Emerita of the Practice, Heller School for Social Policy and Management, Brandeis University, USA

Sushrut Jadhav, Clinical Associate Professor of Cross-cultural Psychiatry, University College London; Consultant Psychiatrist \& Medical Lead, Focus Homeless Services, Camden \& Islington NHS Foundation Trust; Clinical Lead, C \& I Cultural Consultation Service; Founding Editor, Anthropology \& Medicine journal (Taylor and Francis, United Kingdom); Research Associate, Department of Anthropology, SOAS, London, United Kingdom

Chinnaiah Jangam, Assistant Professor of History, Carleton University, Canada

S. Japhet, Vice Chancellor, Bengaluru Central University, Bengaluru, India

Sangeeta Kamat, Professor of Education, University of Massachusetts at Amherst, USA

Joel Lee, Assistant Professor of Anthropology, Williams College, USA

David Mosse, Professor of Social Anthropology, SOAS, University of London, United Kingdom

Samuel L. Myers, Jr., Roy Wilkens Professor of Human Relations and Social Justice and Director, Roy Wilkins Center for Human Relations and Social Justice, Humphrey School of Public Affairs, University of Minnesota, USA

Balmurli Natrajan, Professor and Chair, Department of Anthropology, William Patterson University, USA
Purna Nepali, Associate Professor, Kathmandu University, Nepal

Katherine S. Newman, Senior Vice President for Academic Affairs, University of Massachusetts system, Torrey Little Professor of Sociology, USA

Martha C. Nussbaum, Ernst Freund Distinguished Services Professor of Law and Ethics, Law School and Philosophy Department, University of Chicago, USA

Devan Pillay, Associate Professor and Head, Department of Sociology, University of Witwatersrand, Johannesburg, South Africa

Thomas Pogge, Leitner Professor of Philosophy and International Affairs, Yale University, USA

Christopher Queen, Lecturer on the Study of Religion, and Dean of Students for Continuing Education (Retired), Faculty of Arts and Sciences, Harvard University, USA

Jehan Raheem, Former Founding Director, Evaluation Office, United Nations Development Programme and Former UNDP Resident Representative, Burma (Myanmar)

Anupama Rao, Associate Professor of History, Barnard and Columbia Universities, USA

Amilcar Shabazz, Professor, W.E.B. Du Bois Department for Afro-American Studies, University of Massachusetts at Amherst, USA

A.B. Shamsul, Distinguished Professor and Founding Director, Institute for Ethnic Studies, The National University of Malaysia

Kalinga Tudor Silva, Professor Emeritus of Sociology, University of Peradeniya, Sri Lanka; Research Director, International Centre for Ethnic Studies, Colombo, Sri Lanka

Harleen Singh, Associate Professor of Literature and Women's, Gender and Sexuality Studies, Brandeis University, USA

Ajantha Subramanian, Professor of Anthropology and South Asian Studies, Social Anthropology Program Director, Harvard University, USA

Abha Sur, Scientist in the Science, Technology and Society Program; Senior Lecturer, Program in Women and Gender Studies, Massachusetts Institute of Technology, USA

Goolam Vahed, Associate Professor, History, Society \& Social Change Cluster, University of Kwazulu-Natal, South Africa

Gowri Vijayakumar, Assistant Professor of Sociology and South Asian Studies, Brandeis University, USA

Annapurna Waughray, Reader in Human Rights Law, Manchester Law School, Manchester Metropolitan University, UK

Cornel West, Professor of the Practice of Public Philosophy, Harvard Divinity School, USA 
Copyright (c) 2021 CASTE: A Global Journal on Social Exclusion ISSN 2639-4928

\section{brandeis.edu/j-caste}




\section{EDITORIAL AND INTRODUCTION}

Laurence Simon and Sukhadeo Thorat

-.......VII-X

\section{ARTICLES}

A Commentary on Ambedkar's

Posthumously Published

"Philosophy of Hinduism" - Part III

Rajesh Sampath

....... 219-234

Norm Entrepreneurship at the UN - Dalits and Communities Discriminated on Work and Descent Paul Divakar Namala

....... 235-264

Ambedkar and the Buddha's Sangha:

A Ground for Buddhist Ethics Timothy Loftus

....... 265-280

Reading Dalit Autobiographies in English:

A Top Ten List Christopher Queen

...... 281-294

Ethnic Identity, Discrimination and the Shaping of Remittance Culture in Ghana Joseph Kweku Assan

...... 295-314

A Critique of Sanskritization from Dalit/ Caste-Subaltern Perspective Ishita Roy 315-326

Exclusion of Tribal Women from Property Inheritance Rights: A Study of Tripuri Women of India Ashim Shil and Hemraj P Jangir $327-340$

On the Margins of Healthcare: Role of Social Capital in Health of Migrants in India Shriyuta Abhishek and Nanda Kishore Kannuri

........ 341-358

Tending Immanence, Transcending Sectarianism: Plane of Mixed Castes and Religions Roshni Babu

....... 359-374

\section{FORUM}

Ari Varutada A Poem by

Chandni Girija

375-378

Reflection A Poem by Gaurav J. Pathania 379-380
BOOK, ESSAY, FILM REVIEW

Spotted Goddesses: Dalit Women's Agencynarratives on Caste and Gender Violence Balmurli Natrajan

...... 381-390

Dalit-Bahujan Feminism: A Newly Emerging

Discourse Kancha llaiah Shepherd

....... 391-396

Retro-Modern India Zeeshan Husain

....... 397-406

Caste, Gender and Fire in Maadathy: an Unconventional Fairy Tale

Roja Suganthy-Singh

....... 407-410 